\title{
CFD Modeling of a Headbox with Injecting Dilution Water at Different Step Diffusion Tube
}

\author{
Darong Tang and Jinsong Zeng ${ }^{*}$ \\ State Key Laboratory of Pulp and Paper Engineering, School of Light Industry and Engineering, South China University of \\ Technology, Guangzhou 510640, China \\ ${ }^{*}$ Corresponding author
}

\begin{abstract}
The headbox is heart of the paper machine in paper industry. In the paper, the flow dynamics of the dilution water that adjusts the consistency of the fluid in a hydrodynamic headbox was studied by performing computational fluid dynamics (CFD) simulations. A standard k- $\varepsilon$ turbulence model was used in conjunction with a study of the mass diffusion in the turbulent flow based on the species transport approach. A numerical simulation of headbox was performed using a SIMPLE scheme for the pressure-velocity coupling. The simulation results show that when dilution water was injected at different sites above the inlet of the step diffusion tube, the water content at the outlet of the slice channel conformed to a standard normal distribution. Furthermore, the site at which the dilution water is injected strongly affects the turbulent kinetic energy.
\end{abstract}

Keywords-computational fluid dynamics; headbox; consistency distribution; turbulent kinetic energy

\section{INTRODUCTION}

A headbox is one of the key pieces of equipment used in papermaking machines. Its duty is to keep the pulp suspension uniformly distributed from the outlet of the headbox to the forming wire. The pulp suspension with sufficiently high turbulent intensity can prevent fibers from flocculating. A hydraulic headbox with the dilution control can adjust the CD basis weight distribution, avoiding the need to change slice opening profile and eliminating the bias and cross-flow phenomena caused by traditional methods.

Theoretical hydrodynamics can provide the background for designing the headbox so that the outlet of the slice channel will discharge the pulp suspension uniformly. Because the fiber network has characteristics of flocculation in the flow channel, a large number of scholars have studied fiber suspensions[1-5]. Full-scale experiments can be expensive; therefore, it would be beneficial to have a computational model that provides information on the effects of various design elements on the flow. Using numerical simulations like CFD, we can better understand the mixing characteristics of the dilution water and the characteristics of the flow in the step diffusion tube, equalizing chamber, turbulence generator, etc [6-13].

To gain a better understanding of the flow field caused by injecting dilution water from different locations in a hydraulic headbox, the study based on the flow channel of a headbox in engineering practice, follows our previous studies that CFD modeling of a headbox with injecting dilution water in a central step diffusion tube [14-15]. In this paper, a standard k- $\varepsilon$ turbulence model with a species transport approach, was used to describe the flow. The results showed that at the speed of $800 \mathrm{~m} / \mathrm{min}$, the hydrodynamic characteristics of the flow field were closely related to the injecting sites, diluted water would affect the consistency, and turbulence kinetic energy of the flow channel in the hydrodynamic headbox.

\section{MATERIALS AND METHODS}

In the previous studies, the experiment and model validation of a headbox with injecting dilution water in a central step diffusion tube have been introduced ${ }^{[19]}$. Meanwhile, the mesh and computational method have also been discussed. Based on the same model, CFD modeling of a headbox with injecting dilution water at a different step diffusion tube, was performed using the ANSYS 12.0 as the previous studies. To model the turbulence, a standard k- $\varepsilon$ model was combined with a mass diffusion in turbulent flows species transport approach in mixed flow simulations of the viscous model. SIMPLE (Semi-Implicit Method for Pressure Linked Equations) schemes were used for pressure velocity coupling, whereas standard was used as the spatial discretization method for pressure. A second-order implicit scheme was used for advancing the time.

In the headbox model, as shown in Figure 1, the main stream entering the inlet of the seven-step diffusion tubes was mixed with diluted water injected from its top, then passing through the step diffusion tube, equalizing chamber, turbulence generator and slice channel. The flow out of the slice channel was ejected. The flow from the seven-step diffusion tubes was treated as having equal flux, because the speeds in the manifold header were equal and the step diffusion tubes were the same sizes. Therefore, the computational model included only the step diffusion tube, the equalizing chamber, the turbulence generator and the slice channel.

In Figure 1, the computational domain was from $\mathrm{x}=-57.5$ $\mathrm{mm}$ to $\mathrm{x}=57.5 \mathrm{~mm}, \mathrm{y}=-235 \mathrm{~mm}$ to $\mathrm{y}=235 \mathrm{~mm}$, and $\mathrm{z}=-560 \mathrm{~mm}$ to $\mathrm{z}=1290 \mathrm{~mm}$, where $\mathrm{x}, \mathrm{y}$, and $\mathrm{z}$ represented the three directions in the Cartesian coordinate system. The dilution site was $10 \mathrm{~mm}$ from the inlet of the main stream. The diameter of the dilution water inlet was $8 \mathrm{~mm}$. The small and large pipes of the diffusion tubes were $20 \mathrm{~mm}$ and $30 \mathrm{~mm}$ in diameter, respectively, and $250 \mathrm{~mm}$ long. The inside of the equalizing chamber was approximately $450 \times 250 \times 115 \mathrm{~mm}$. The section of the turbulence generator changed from a circle with a diameter of $35 \mathrm{~mm}$ to a rectangle with dimensions of $55 \times 18$ 
$\mathrm{mm}$; this part was $400 \mathrm{~mm}$ long. The rectangular outlet of the slice channel had dimensions of $470 \times 18 \mathrm{~mm}$ and was $700 \mathrm{~mm}$ long. In the model, the main stream entering the seven-step diffusion tubes was mixed with dilution water upstream of the step diffusion tubes, then passed through the equalizing chamber and the turbulence generator, and finally reached the slice channel. The flow was injected from the slice channel.

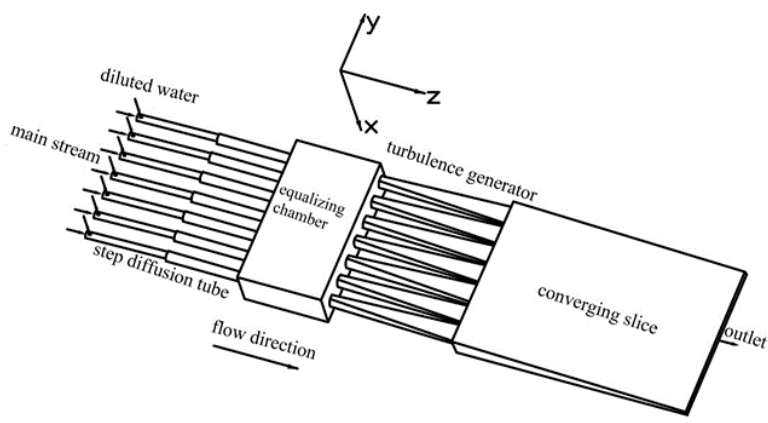

FIGURE I. COMPUTATIONAL DOMAIN OF THE HEADBOX MODEL

The low consistency pulp in the headbox is one kind of non-Newtonian viscoplastic fluid. The viscoplastic fluid behaves as the Newtonian fluid when the shear stress exceeds the yield stress ${ }^{[21,22]}$. With medium-high speed, the flowing pulp of low consistency belongs to fully developed turbulence. When the shear stress exceeds the yield stress, the viscosity of pulp is constant as the Newtonian fluid. The flowing pulp of low consistency assumed to contain two fluids: one was water and the other was the low consistency pulp. With the consistency of the diluted pulp was $0.3 \%$ and the main stream was $1 \%$, the CFD model was simulated by the listed parameters of Table 1.

TABLE I. SIMULATION PARAMETERS FOR CFD MODEL

\begin{tabular}{|c|c|c|}
\hline Parameter & Water & Low consistency pulp \\
\hline Density $\left(\mathrm{kg} / \mathrm{m}^{3}\right)$ & 998.2 & 1045 \\
\hline Viscosity $(\mathrm{pa} \cdot \mathrm{s})$ & 0.001 & 0.0018 \\
\hline Diffusivity $\left(\mathrm{m}^{2} / \mathrm{s}\right)$ & $2.88 \times 10^{-5}$ & $2.88 \times 10^{-5}$ \\
\hline $\begin{array}{c}\text { Thermal conductivity } \\
(\mathrm{w} / \mathrm{m} \cdot \mathrm{k})\end{array}$ & 0.6 & 0.46 \\
\hline $\begin{array}{c}\text { Specific heat capacity } \\
(\mathrm{j} / \mathrm{kg} \cdot \mathrm{k})\end{array}$ & 4182 & 1380 \\
\hline
\end{tabular}

To clarify the location of the dilution water sites, as shown in Figure 2, " 4 " is the center step diffusion tube, " 1 " and " 7 " are the outside of step diffusion tubes, " 2 " and " 6 " are neighbors of " 1 " and " 7 " , " 3 " and " 5 " are next to " 4 ". This paper will analyze the dilution water sites combination where the dilution water is injected from, including " 26 " combination, "3 5" combination, "1 7" combination, "4" and "all". For example, "all" refers to that all dilution water sites are injected by dilution water, " 35 " combination refers to that " 3 " and " 5 " dilution water sites are injected by dilution water, and the dilution water is not injected from 1, 2, 4, 6, and 7 simultaneously.

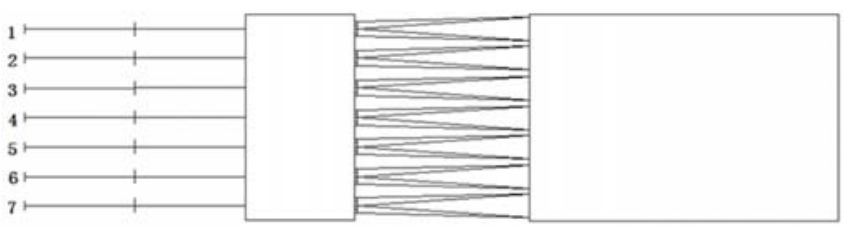

FIGURE II. SCHEME OF DILUTION WATER SITES

\section{RESUlTS AND DisCUSSION}

A. Consistency of the Flow at the Slice Outlet of $x=0.030 \mathrm{~m}$, $z=1.29 \mathrm{~m}$

The main stream was mixed with the dilution water injected at seven locations such as "1" "2" "3" "4" "5" "6"and "7", making the water content at the outlet different from the different injection sites. As shown in Figure 3, when the main stream was mixed with the dilution water injected at sites of "3 5 " combination and " 4 ", the curves were similar, the fluid's water content was the highest in the middle of the outlet, as the distance from the center of the outlet increases, the water content decreased.

To clarify the functional relationship between the location of the outlet and its water content, a distribution equation was deduced by simplifying the theoretical formulae. As shown in Figure 3, a Gaussian function was used to fit the curve, the abscissa value was at $\mathrm{x}=30 \mathrm{~mm}, \mathrm{z}=1290 \mathrm{~mm},-235 \mathrm{~mm} \leq$ $\mathrm{y} \leq 235 \mathrm{~mm}$ and the ordinate value was the water content. A Gaussian function was as followed:

$$
Y=\frac{A}{\sqrt{2 \pi} \sigma} e^{-\frac{\left(X-X_{0}\right)^{2}}{2 \sigma^{2}}}+Y_{0}(A>0)
$$

As shown in Figure 3, the fitting coefficient could be greater than 0.99 . This showed that the simulation results were in good agreement with the fitting values. To simplify the function given in equation (1), we set:

$$
\begin{gathered}
\frac{Y-Y_{0}}{A}=\Delta Y \\
X-X_{0}=\Delta X
\end{gathered}
$$

Substituting the above two equations into equation (1) gave the following:

$$
\Delta Y=\frac{1}{\sqrt{2 \pi} \sigma} e^{-\frac{\Delta X^{2}}{2 \sigma^{2}}}
$$

Continuing the analysis of equation (1), (2), (3) and (4), $\Delta Y$ was considered the "equivalent consistency" at the outlet of the converging slice, $Y_{0}$ was the offset of the lowest point of the curve on the abscissa; the horizontal axis was going in the ydirection, $\quad X_{0}=0 \quad, \quad-235 \mathrm{~mm} \leq X \leq 235 \mathrm{~mm}$ 
Because $\frac{Y-Y_{0}}{A}=\Delta Y, \Delta Y$ had a linear relationship with $Y$. In the expression (1), as $A>0$, it meant the curve opening was downward. We could conclude that when water was injected at sites of " 3 " combination and " 4 ", the water content of the fluid at the outlet of the converging slice followed a standard normal distribution.

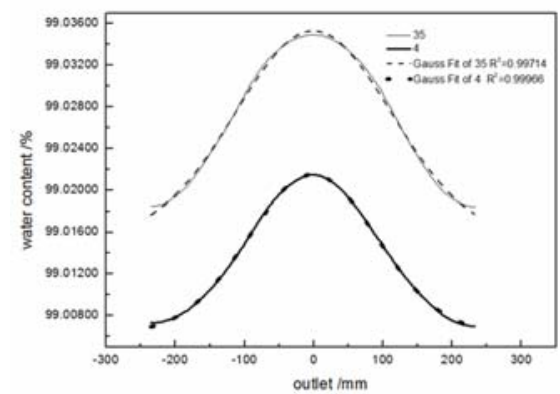

FIGURE III. WATER CONTENT AT OUTLET OF “3”AND "5"COMBINATION AND "4" SITE

As shown in Figure 4, Figure 5 and Figure 6, the water content were demonstrated when the dilution water was injected at sites of " 2 6" combination, " 17 " combination and "all". At $\mathrm{x}=30 \mathrm{~mm}, \mathrm{z}=1290 \mathrm{~mm},-235 \mathrm{~mm} \leq \mathrm{y} \leq 235 \mathrm{~mm}$, i.e., at the outlet of the converging slice, the same location as that represented in Figure 3, the main streams were mixed with the dilution water at locations "2 6" combination, "1 7" combination and "all", the water content was the least at the center of the outlet, which was at $x=30 \mathrm{~mm}, \mathrm{y}=0 \mathrm{~mm}, \mathrm{z}=1290$ $\mathrm{mm}$, as the distance from the injected site increased, the water content decreased.

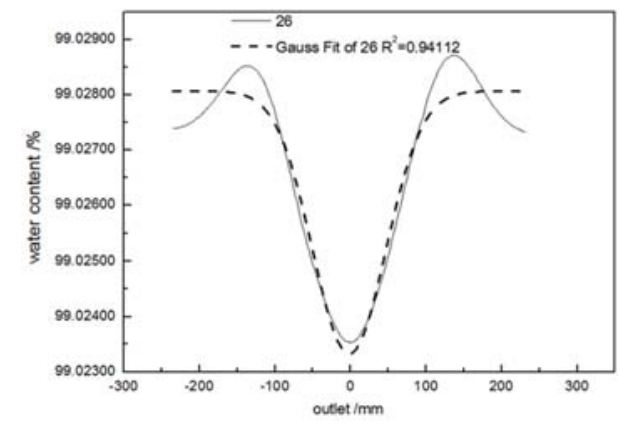

FIGURE IV. WATER CONTENT AT OUTLET OF " 2 6"COMBINATION

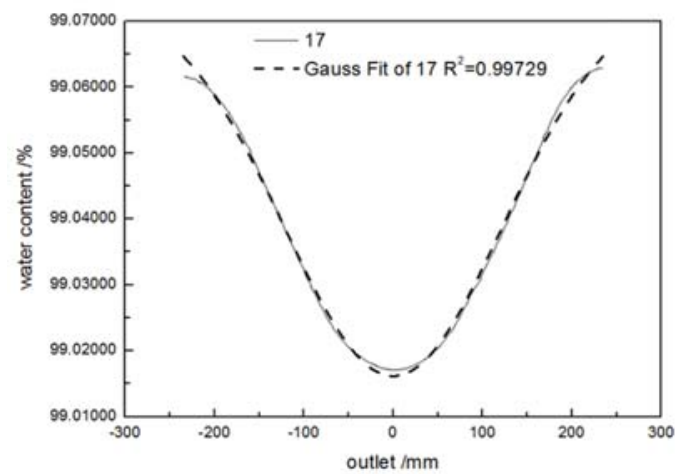

FIGURE V. WATER CONTENT AT OUTLET OF “1 7”COMBINATION

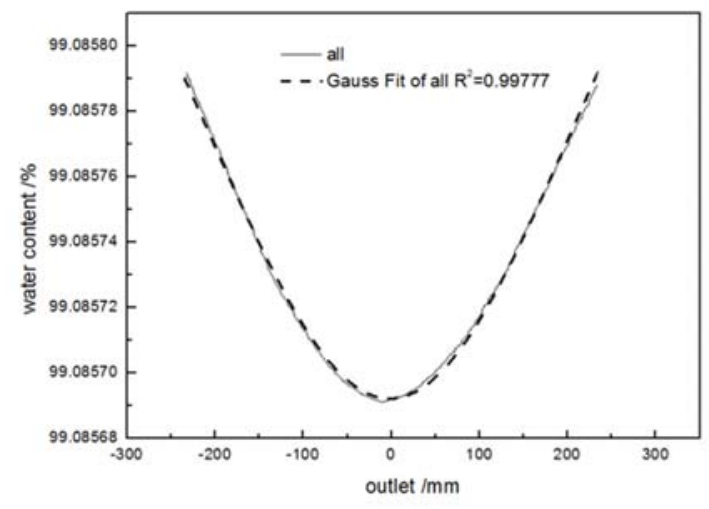

FIGURE VI. WATER CONTENT AT OUTLET OF “ALL" COMBINATION

To clarify the functional relationship between the locations of the outlet and its water content, a distribution equation was deduced by simplifying theoretical formulae. As shown in Figs. 4, 5, and 6, Gaussian function was used to fit the curve, the abscissa value was at $x=30 \mathrm{~mm}, \mathrm{z}=1290 \mathrm{~mm},-235 \mathrm{~mm} \leq$ $\mathrm{y} \leq 235 \mathrm{~mm}$ and the ordinate value was the water content. A Gaussian function was as followed:

$$
Y=\frac{A}{\sqrt{2 \pi} \sigma} e^{-\frac{\left(X-X_{0}\right)^{2}}{2 \sigma^{2}}}+Y_{0}(A<0)
$$

Using this Gaussian function to fit the curves shown in Figs. 4, 5 and 6, there were good results in fitting coefficient, one was greater than 0.94 for Figure 4, and the other two were greater than 0.99 . To simplify equation (5), we set:

$$
\begin{gathered}
\frac{Y-Y_{0}}{A}=\Delta Y \\
X-X_{0}=\Delta X
\end{gathered}
$$

By substituting the above two equations into equation (5), we derived the following formula:

$$
\Delta Y=\frac{1}{\sqrt{2 \pi} \sigma} e^{-\frac{\Delta X^{2}}{2 \sigma^{2}}}
$$

Continuing the analysis of equation (5), (6), (7) and (8), $\Delta Y$ was considered as the "equivalent consistency" at the outlet of the converging slice, $Y_{0}$ was the offset of the lowest point of the curve on the abscissa; the horizontal axis was going in the $y$ direction, $X_{0}=0,-235 \mathrm{~mm} \leq X \leq 235 \mathrm{~mm}$. Because $\frac{Y-Y_{0}}{A}=$ $\Delta Y, \Delta Y$ had a linear relationship with $Y$. In the expression (5), as $A<0$, it meant the curve opening was upward. Therefore, we concluded that when water was injected at locations " 26 " combination, "1 7" combination and "all" locations, the 
equivalent consistency at the outlet of the converging slice followed a standard normal distribution.

\section{B. Water Content at Different Z Locations}

When dilution water was injected at sites of "2 6" combination, the water content at different $\mathrm{z}$ locations after the diluted water had mixed with main stream was shown in Figure 7. At $\mathrm{z}=50 \mathrm{~mm}$ in the equalizing chamber, the water content appeared peaks at $\mathrm{x}=0 \mathrm{~mm}, \mathrm{y}=-134 \mathrm{~mm}$ and at $\mathrm{x}=0 \mathrm{~mm}, \mathrm{y}=134$ $\mathrm{mm}$, the two locations were just downstream of the sites at which the dilution water was injected, where the flows from the two injection sites did not completely mix with the main flow. On both sides of equalizing chamber, the water content was the lowest because the injected water had not arrived there. At $\mathrm{z}=300 \mathrm{~mm}$ (in the turbulence generator) and $\mathrm{z}=1000 \mathrm{~mm}$ (in the converging slice), the flows were more uniformly mixed and the consistency became stable, and the consistency differences decreased.

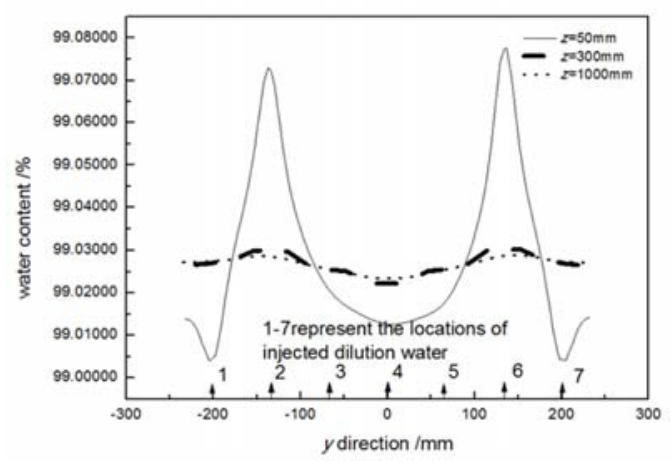

FIGURE VII. WATER CONTENT OF "2 6" COMBINATION IN DIFFERENT Z LOCATIONS ( $\mathrm{X}=0$ )

Accordingly, when the dilution water was injected at the locations of " 35 "combination and " 4 ", after the diluted water had mixed with main stream, the water contents at different $z$ locations were shown in Figs. 8 and 9. At $\mathrm{z}=50 \mathrm{~mm}$ (in the equalizing chamber), the water content appeared to have two peaks at the downstream sites of " 35 " combination in Figure 8, they were closer than the injection sites" 26 " combination in Figure 7. In Figure 9, there was only one peak because of one "4" site. In Figs. 8 and 9, as the flows moved from the step diffusion tube to the converging slice, they became more uniformly mixed. While in the "all" combination, as shown in Figure 10, there were six peaks at $\mathrm{z}=50 \mathrm{~mm}$ because of the coherence of injecting dilution water between " 26 ", " 35 " "17", and " 4 " nearly equals $0 \mathrm{~mm}$. In Figure 10, the water content differences were the smallest in the figures because of seven injected sites. In Figure 11, the water content appeared to have two peaks at the downstream sites of " 17 " combination. Similarly, as the mixed stream flowed to the turbulence generator and slice channel, the water content curve became more and more smooth.

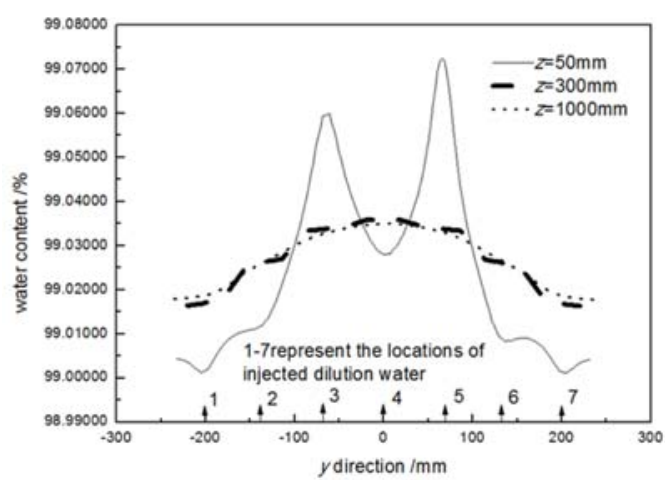

FIGURE VIII. WATER CONTENT OF “3 5" COMBINATION IN DIFFERENT Z LOCATIONS ( $\mathrm{X}=0$ )

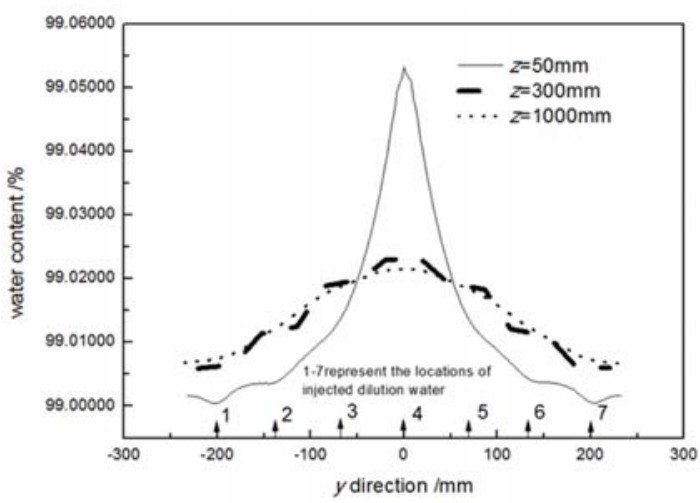

FIGURE IX. WATER CONTENT OF "4" COMBINATION IN DIFFERENT Z LOCATIONS $(\mathrm{X}=0)$

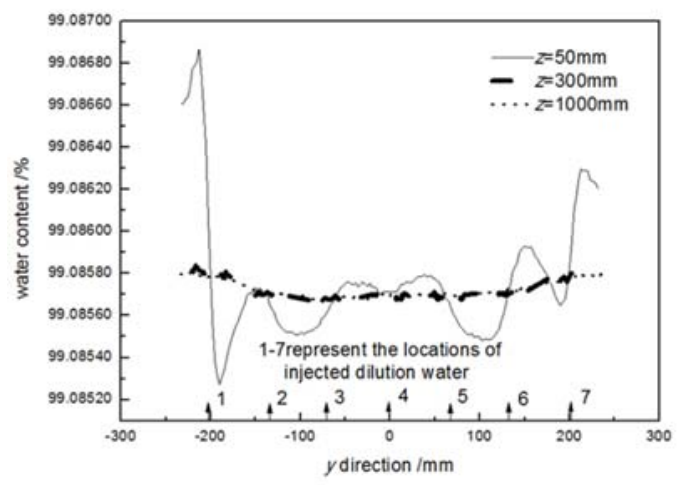

FIGURE X. WATER CONTENT OF “ALL” COMBINATION IN DIFFERENT Z LOCATIONS ( $\mathrm{X}=0$ ) 


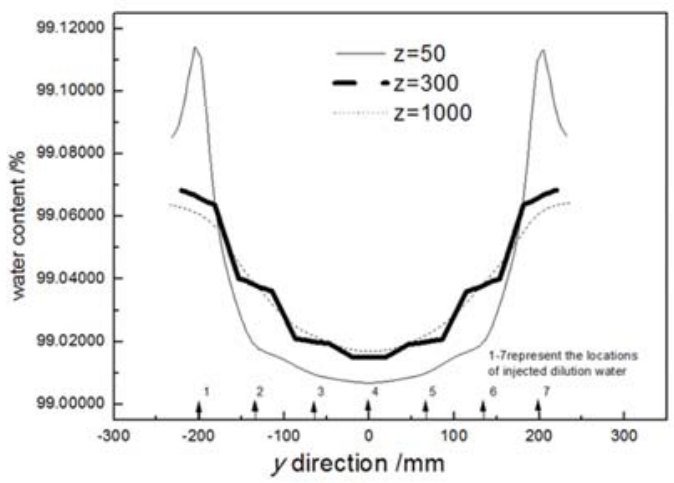

FIGURE XI. WATER CONTENT OF " 17 " COMBINATION IN DIFFERENT Z LOCATIONS ( $\mathrm{X}=0$ )

\section{The Turbulent Kinetic Energy at $x=0 \mathrm{~m}, y=0 \mathrm{~m}$}

In order to illustrate the turbulent kinetic energy in Figs. 12, clearly, some critical positions were noted by using the following letters:

a- referred to the location where the dilution water was injected.

$\mathrm{b}$ - referred to the connection between the small and large diffusion tube.

c- referred to the entrance of equalizing chamber.

d- referred to the entrance of turbulence generator.

e- referred to the entrance of slice channel.

$\mathrm{f}$ - referred to the location $0.1 \mathrm{~m}$ away from the entrance in the slice channel.

Figs. 12 illustrated the turbulent kinetic energy at different $\mathrm{z}$ locations for $\mathrm{x}=0 \mathrm{~m}, \mathrm{y}=0 \mathrm{~m}$ at a flow speed of $800 \mathrm{~m} / \mathrm{min}$. As seen from the figures, when dilution water was injected into some step diffusion tubes at different combinations, peaks appeared near the inlets $(\mathrm{z}=-0.56 \mathrm{~m})$ where the dilution water was injected into the main stream from the vertical direction, and the entrance of the turbulence generator $(\mathrm{z}=0.2 \mathrm{~m})$ where the change of flow section shape was sharp in the experimental model, the turbulent kinetic energy and dissipation rate were at peaks, they caused intensive turbulence.

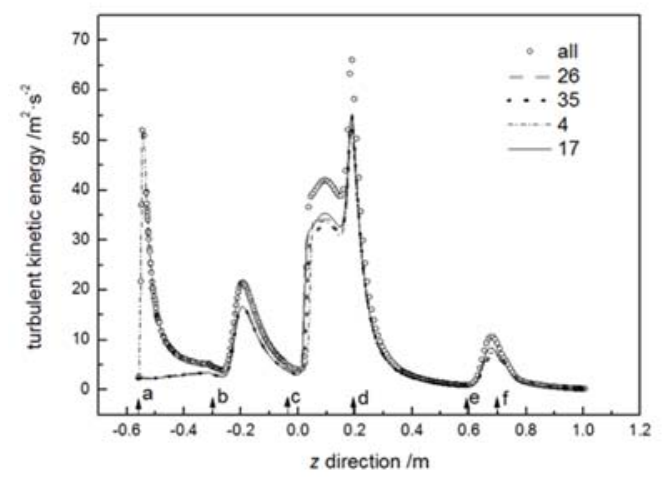

FIGURE XII. TURBULENT KINETIC ENERGY IN Z DIRECTION(X=0 $\mathrm{M}, \mathrm{Y}=0 \mathrm{M}$ )
At the locations of " 35 "combination, "2 6" combination or "1 7" combination, no water was injected from the central step diffusion tube, the turbulent kinetic energies were lower. Similarly, when the mixed flow consisting of the main stream and dilution water arrived at the entrance of the turbulence generator, the turbulent kinetic energies were at peaks, but they were lower than "all" combination and " 4 " site.

When the mixed flow entered the thick pipes of the step diffusion tubes, the turbulent kinetic energy began to increase slightly because the step diffusion tubes suddenly increased in size. In the equalizing chamber, the turbulent kinetic energy of the mixed flow gradually became calm and steady. As the mixed flow passed through the turbulence generator and slice channel, the turbulent kinetic energy of the mixed flow became more stable, except for a small increased between the turbulence generator and the slice channel due to the change in the sizes.

\section{CONCLUSION}

The flow dynamics of the dilution water that adjusts the consistency of the fluid in a hydrodynamic headbox has been studied by using CFD simulations. The results show that Standard k- $\varepsilon$ turbulence models in conjunction with the mass diffusion in turbulence flow species transport approach can predict CFD model of a headbox for injecting dilution water at different locations with a flow speed of $800 \mathrm{~m} / \mathrm{min}$. The water content has a standard normal distribution at the outlet of the slice channel. The turbulent kinetic energy reaches the peaks at the downstream sites where the dilution water is injected. Pulp suspension becomes calm and stable as it enters the equalizing chamber, and the equalizing chamber has a role in eliminating and attenuating the energy fluctuations. The dilution water injection locations and the structure of headbox are the two important factors that affect the flow patter of pulp suspension.

\section{ACKNOWLEDGMENT}

The authors are grateful for the support of National Key R\&D Program of China (Number: 2017YFB0307902), 111 plan, and Guangdong provincial science \& technology plan projects (Number: 2015B020241001).

\section{REFERENCES}

[1] Ullmar M, Norman B. Observation of fiber orientation in a headbox nozzle at low consistency[C]//ENGINEERING AND PAPERMAKERSCONFERENCE-. TAPPI PRESS, 1997: 865-874.

[2] Ullmar M. On fiber alignment mechanisms in a headbox nozzle[D]. Institutionen för pappers-och massateknologi, 1998.

[3] Pantaleo S B. A new headbox design featuring consistency profiling decoupled from fiber orientation response[J]. Tappi journal (USA), 1995.

[4] Zhang X. Fiber orientation in a headbox[D]. University of British Columbia, 2001.

[5] Olson J A, Frigaard I, Chan C, et al. Modeling a turbulent fibre suspension flowing in a planar contraction: The one-dimensional headbox[J]. International Journal of Multiphase Flow, 2004, 30(1): 5166.

[6] Zeng J S, Huang H, Feng Y C, et al. A CFD Model of a Headbox for Injecting Dilution Water at Different Locations Along a Step Diffusion Tube $[\mathrm{C}] / /$ International Conference on Test, Measurement and Computational Methods. 2015. 
[7] Avikainen M, Hämäläinen J, Tarvainen P. Paper physics HOCS Fibre: CFD-based software for fibre orientation profile optimization for conventional and dilution headboxes[J]. Nordic Pulp and Paper Research Journal, 2010, 25(4): 456.

[8] Svenning E, Mark A, Edelvik F, et al. Multiphase simulation of fiber suspension flows using immersed boundary methods[J]. Nordic Pulp and Paper Research Journal, 2012, 27(2): 184.

[9] Park K, Hong C H, Lee J, et al. Flow control and optimal shape of headbox using CFD and SMOGA[J]. Int. J. Aerosp. Mech. Eng, 2010, 4(3): 143-148.

[10] Yu D. Study on the rheological properties of pulp fiber suspensions and CFD simulation of pulp flow in special shaped channel[D]. South China University of Technology, 2015.

[11] Li A C, Rogers T D, Shands J A. Mixing intensity analysis of a 2-layer stratified headbox jet[J]. Research, 2000.

[12] Hämäläinen J. Mathematical modelling and simulation of fluid flows in the headbox of paper machines[M]. Jyväskylän Yliopisto, 1993.

[13] Pougatch K, Salcudean M, GARTSHORE I, et al. A computational study of the fluid flow through a hydraulic headbox[J]. Tappi journal, 2005, 4(10): 3-8.

[14] Yang X, Zeng J, Chen K, et al. CFD modeling of a headbox with injecting dilution water in a central step diffusion tube[J]. Chinese Journal of Chemical Engineering, 2016, 24(10): 1313-1324.

[15] Fluent Inc, Fluent 6 user's guide, Lebanon, USA, 5-10 (2001). 